\title{
Assisting Engineering Students in Acquiring Academic Literacy Skills
}

\author{
Mary Hatakka \\ The Petroleum Institute, Abu Dhabi, UAE
}

\begin{abstract}
Academic literacy skills are essential skills for students in higher education and can bedefined as writing strategies, library research strategies and general study skills [1]. However, courses providing this kind of knowledge are often not well received by engineering students or engineering faculty [2]. Successful attempts have been made to introduce academic literacy skills into various disciplines [1,3, 4], but despitethe positive reception of piloted courses, the subsequent application of such experimental models is not common. In the current study it is suggested that this stems from the basic differences between the epistemologies of humanities and engineering. While Humanities matters can be seen as strongly contextual,science is related to theory and facts [5] as well as to entities and substructures. In order to promote the teaching of academic literacy skills in engineering colleges, it is therefore suggested that an instructional model following the epistemology of engineering should be adopted.
\end{abstract}

\section{Introduction}

Students in higher education institutes (HEIs) need to acquire academic literacy skills, in other words, skills which enable them to read academic texts, to write in an academic way and to do research. Many of them also need to develop their general study skills. Moreover, the knowledge that they acquire in their studies at HEIs is still mainly tested using written exams, and good academic literacy skills enable students to express themselves more articulately, be it orally or in writing. Experience and anecdotal evidence have shown that students who arrive inhigher education (HE) well-equipped in such skills from school continue to thrive, whereas many initially weak students are not able to develop these skills to the extent required for success in higher education.

In addition, as academic writing courses were originally developed for Humanities students and taught mainly in the English departments of HEIs [6], it is possible that students in other disciplines might struggle to understand the rationale behind the necessity to acquire such skills [2],or the skills may seem irrelevant to their specific field. This is especially true of students studying in higher education for a professional degree such as business or engineering. In fact, in a recent study both engineering students and instructors were shown to be opposed to an emphasis on academic literacy skills [2]. It is most likely because even though academic literacy skills are seen to develop students' critical thinking skills, they do not specifically promote what the Royal Society of Engineering calls Engineering Habits of Mind [7]. These leads to the argument that perhaps a model for the instruction of academic literacy skills which incorporates Engineering Habits of Mind would be better received in departments of engineering by both students and instructors.

\section{Background}

As the student population has become more diverse and there are multiple tracks for entering HE, some students may be lacking inbasics in academic literacy skills on entering higher education. This phenomenon was recognized both in the USA and in the UK already in the 1960s and 1970s, when a more diverse student population started entering HEIs [8]. At the time, the solution was to tackle the students' shortcomings, as they were seen to be, by providing courses in writing across the curriculum (WAC) andwriting in the disciplines (WID) in the USA [9] and in English for academic purposes and study skills in the UK [3].

Based on the traditions in the USA and the UK, [10] opted to investigate the issues surrounding these skills from a more holistic standpoint in the 1990s. The idea was to try and understand how the skills and skill sets were situated within higher education, as opposed to seeing the lack of such skills as a deficiency on the students' part. This led to a new 
framework which they called academic literacies (ACLITS). It consists of three overlapping areas comprising study skills, academic socialization and academic literacies [10].Study skills refers to "a set of atomized skills which students have to learn and which are then transferable to other contexts" [11, p. 348]. Bluntly they could be seen as the grammar, vocabulary, punctuationand organizational issues in writing. Academic socialization encompasses the notion of study skills and the ways in which students adapt to life at college both academically and socially. Research pertaining to academic socialization includes studies on students' initiatives to engage in their studies in order to become successful in HE. The highest level which encompasses both study skills and academic socialization is called academic literacies.Within its scopeis looking at "student writing and learning as issues at the level of epistemology and identities rather than skills or socialization" [11, p. 349].

The practical knowledge gained fromthe study and use of the frameworks of WAC, WID and ACLITS, as well asthe research generated from these areas, have been extremely useful in assisting the development of understanding, teaching and learning academic literacy skills. From a theoretical point of view, the emphasis on dealing with matters at the epistemological level in ACLITS, as prescribed by the academic literacies level, lends itself to the notion that academic literacies could be viewed through the lenses of other disciplines, too. This is especially relevant to students in professional disciplines, such as engineering and business, as theymight possibly benefit more from learning the necessary academic literacy skills using an instructional designmore closely related to the epistemologies of their own disciplines than the Humanities' generated academic literacy skills designs.

Understanding the epistemology of engineering means identifying the kinds of thinking patterns required of an engineer. According to [7, p.24], the six main traits related to engineering thinking are as follows; "systems thinking, seeing whole systems and parts and how they connect, pattern-sniffing, recognizing interdependencies, synthesizing; problem-finding, clarifying needs, checking existing solutions, investigating contexts, verifying; visualizing,being able to move from abstract to concrete, manipulating materials, mental rehearsal ofphysical space and of practical design solutions; improving, restlessly trying to make things better by experimenting, designing, sketching, guessing; conjecturing, thought-experimenting, prototyping, creative problem-solving, applying techniques from different traditions, generating ideas and solutions with others,generous but rigorous critiquing, seeing engineering as a 'team sport', and finally adaptability, testing, analyzing, reflecting, rethinking, changing both in a physical sense and mentally".

Students studying in engineering disciplines are given the opportunity to develop both engineering thinking skills and academic literacy skills throughout their studies. Looking at the engineering habits of mind listed above, it is clear that problemfinding, improving and perhaps visualizing are thinking skills that could be developed through academic literacy skills and in HE in general.

However, academic literacy skills are often taught by non-engineering faculty who often adhere to a Humanities epistemology and hence the instructional approach may not emphasize other engineering habits of mind.These include the traits of systems thinking, creative problem-solving in the way [7] described it and adaptability, which require serious higher order thinking skills. It could be that some of the instructors, due to their own background in humanities, are not aware of the specific differences in habits of mind in different disciplines either, or do not see these habits of mind as something they personally should address. Nevertheless, it has generally been acknowledged that written and oral communication skills, especially in English, have become more and more important for engineers as an increasing amount of industries and businesses have become multinational $[12,13]$. This means that they have to be addressed and that both engineering students and faculty need to recognize this fact.Moreover, communication skills have been identified among the top skills required by employers in many fields, including engineering [14, 15]. In addition, as English has become the lingua franca of business and industries $[16,17]$, one's ability to use it well in situations requiring communications has become more significant. In our increasingly globalized society, good communication skills in English are necessary not only for native speakers of English but also for people for whom English is a foreign language $[18,19]$.

It is suggested here that following some of the principles of the epistemology of engineering or engineering habits of mind in the instruction of academic literacy skills could add value to students' disciplinary knowledge and skills and eventually to the work place [7]. Moreover, it could make academic literacy skills a more acceptable and appreciable subject matter to engineering students and instructors, thus combatting existing reluctance [2]. Some engineering habits of mind are already instilled in the curriculums of engineering HEIs either within engineering subject matters or as curriculum infusedin subjects such as Physics. However, less attention is paid to these skills in study 
skills, academic literacy skills courses and English language courses. While there are more and more international students all over the world, especially in the disciplines of engineering, there is a need for both academic literacy skills as well as engineering habits of mind. With regard to teaching English language skills to international students, it is to be noted, however, that the use these means implies looking at matters at the level of developing thinking skills, not, for example, at teaching engineering students English for specific purposes.

An understanding of the importance of engineering habits of mind was arrived at based on a previous study [20] focusing on academic literacy skills. The purpose of the study [20] was to understand if and how the academic literacy skills of Arab engineeringstudents studying in an Englishmedium engineering HEI improved over time. The aim was to identify indicators of the development of students' academic literacy skills by focusing on the differences between successful and weak students. It was hoped that a better understanding of the underlying issues could be arrived at and ways could be identified to overcome the obstacles in the development of the students' academic literacy skills.

\section{Methods}

In order to understand how the researcher concluded that teaching students academic literacy skills through the utilization of engineering habits of mind, it is important to understand what the original thesis study that the conclusion is based on was about. The approach to the research [20] followed the pragmatic paradigm and the design was a case study. The researcher observed 20 Arab male students on a 16 week academic literacy skills course over a period of ten weeks.

The data gathered were a mixture of quantitative and qualitative data and the analysis was predominantly interpretive, although some numerical data were analyzed quantitatively. Based on the final grade for the academic literacy skills the students were grouped into successful, average and weak students. Six data collection methods were used comprising surveys, grade comparisons, written assignments, semi-structured interviews and classroom and instructor observations. The core of the data were three consecutively completed written assignments (a literature review, a proposal and a final report) completed by each student and collected over a period of ten weeks. The other data were predominantly used to understand and support findings from the assignments. The students' final course grades were also taken into consideration.
In addition, a further case study within the main one included an in-depth analysis of two successful and two weak students. It was done to show how individual experience was reflected in the results gathered on the 20 students who formed the main case that was studied and to provide more depth to the main case study.

\section{Results}

The advantage of using a case study is that it provides rich data for analysis. It is the kind of data that is practically impossible to obtain, for instance, from a quantitative data gathering instrument such as a questionnaire. The broad categories for the analysis of the results from [20] were obtained from [1]. They are the three categories of academic literacy skills; writing strategies, library research strategies and general study skills [1]. Then afurther, more meticulous analysis was done using the categories provided by the ACLITS framework [10] mentioned above.

\subsection{Writing strategies}

In the category ofwriting strategies [1] the most obvious matters which students had problems with reflected their poor digital literacy skills. These included a lack of knowledge about how to use online dictionaries and translation programs from their mother tongue (L1) into English and vice versa. As a result students chose the wrong word or a phrase that was a literal translation of the equivalent one in their L1. In addition the students did not take advantage of spellchecker option in MS-Word, which was evident from the kinds of spelling mistakes that remained in the submitted assignments. This was also reflected in a clear lack of proofreading skills. Due to the fact that the three major written assignments studied fed into each other, it became evident that there was a tendency to ignore feedback - or an unwillingness to respond to it. In fact, many of the students' final reports included mistakes that had been pointed out by the instructor in the first assignment.

Moreover, students had problems tackling the layout of their documents which they had been requested to submit using MS-Word. There were inconsistent paragraph breaks, margins, headings and even the types of font varied in the same document. Problems with layout issues were also evident in their lists of references. They had been requested to use the IEEE citation system in order to familiarize themselves with the kind of numerical citation systems typical in engineering writing, but making 
the reference list look the way it should in IEEE seemed to be a challenge for students.

\subsection{Library research strategies}

Reviewing students' library research strategies [1], it was clear that students struggled to find appropriate information. They also did not seem to understand the need for them to move from simplistic explanations to complex ones when they searched for information. Instead, many of them chose journal articles that were loosely related to their research topics. However, the ideas and language in the selected articles were often too demanding for them to understand the gist of the ideas presented properly.In addition, many students did not really understand the importance of using citation systems and avoiding plagiarism, in other words, the idea of sharing and creating knowledge in higher education. All the assignments were run through a plagiarism detection program and while students had been informed about this in advance, there were a few incidents of plagiarism. In addition, some of the direct quotes from the articles were not really relevant to the context that they were used in, or they were not cited correctly.

\subsection{Study skills}

In the category of study skills [1] students showed varied levels of participation in and volunteering for teacher-fronted activities. This was evident from the video recordings of the lessons during the first ten weeks of the academic literacy skills course. Good students, in other words, students who scored high at the end of the course, were significantly more active in class than average and weak students. The students who fell into the latter two categories showed some distracted and passive behaviors in class, i.e. chatting to friends about topics not related to the lessons and fiddling with their mobile phones instead of paying attention. In fact, some of the average students could have achieved higher grades, if they had not behaved in such distracted ways.

The majority of the students came from a teacher centered, rote-learning environmentat school, where the main responsibility for their learning fell on the teacher. It was clearly difficult for these students to understand the need to do both homework and extra studies outside class in order to fully understand the subject matters being taught. This was clear fromthesurvey and interview results which revealed that many were not prepared to allocate much time to studies outside class. In fact, the amount of time that they spent on studies ranged from only studying for exams to approximately half an hour daily. Moreover, many of the students made no real attempt to improve their English language skills during the course, assuming that the level of language skills that allowed entry into the HEI in question would suffice throughout their studies.

In short, the engineering students in the current study had problems with digital literacy matters and research skills, as well as issues involving reporting research. The students' school-like attitude towards their studies in higher education did not facilitate their learning either.Relating these issues to engineering habits of mind [7], it seems that the students were mainly lacking in skills insystems thinking, problem finding, creative problem-solving, improvementand adaptability.Basically that included all the habits of mind except visualization which was not a focus area on the academic literacies skills course, apart from the charts and graphs that students produced to demonstrate their own survey results. This was very disconcerting, considering the students were all going to major eventually in engineering subjects and also raises the question of the importance of enforcing the thinking skills related to engineering habits of mind.

\section{Discussion}

Generally speaking, it cannot be assumed that incoming students have already acquired engineering habits of mind. However, it could be hoped that most students would show some tendency of thinking along the lines required of an engineer, since they had applied to study in an engineering HEI. Perhaps these skills are more evident in their Math, Physicsand Chemistry classes in their first year.

\subsection{Transition issues}

Some of the issues the students faced are typical transition issues that occur when moving from school to higher education. These include coping with the independent nature of studies and with time management. It could also be that the amount of knowledge and skills that students were expected to develop during an academic literacy skills course felt overwhelming [10] compared to school work, and they did not, therefore, allocate enough time to assignments, or were not used to doing so.

\subsection{Teaching approaches}

Another matter might be the teaching approaches of professors in HE. The approaches can appear to be either more distant, as is the case with mass lectures, 
or more learner-centered, as in tutorials, seminars and smaller groups, compared to the kinds of schools students attended prior to entering HE. Moreover, as many of the students lived in the school dormitories, they did not have the kind of support outside class to deal with the new teaching approaches as they may have had when they were living at home.

\subsection{Lack of digital literacy skills}

It is surprising to realize that not all students are the digital natives their instructors assume them to be. They mostly used their phones, tablets and computers for surfing the internet and social networking, not for work at the HE. While these are valuable skills, developing academic literacy skills requires using electronic dictionaries and translation platforms, using a spellchecker. In addition students are expected to format documents following submission guidelineswhich include guidelines for page numbering, margins, headings, creating tables of content, line spacing, selecting the requested font type and size, inserting pictures, charts and graphs [20]. These are multiple skills and a lack of them raises the question of where students should be expected to acquire such skills.It is debatable whetherstudents leave high school equipped with such skills, or whether HEIs should offer crash courses in these skills or require a certificate of the level of students' digital literacy skills on entry. Moreover, if such skills are to be taught in HE, it is not always clear under which mandate they should be taught.

\subsection{Weak English language skills}

Some students also suffered from weak English language skills. One must bear in mind that because the students in the case study were not native speakers of English, it is possible that there was L1 interference in their choice of vocabulary, sentence structure and punctuation. These problems naturally add to issues related to the students' academic literacy skills in general and specifically to their study skills as defined by [10] or writing skills as defined by [1].

In addition, the fact that there is a spell checker program in a computer was enough for the students to disregard the need to proofread assignments prior to submitting them, which resulted in a sloppy final draft. The students' computers were mainly set in their L1 as the default language and they did not realize that in order to change the default setting to the English language, they needed to reboot the computer. All these issues showed a strong, unquestioning reliance on technology, instead of one's thinking skills. It is also an issue that more and more HEI's should be aware of when attempting to develop students' thinking skills along with disciplinary knowledge.

\subsection{Struggling withresearch sources}

Searching for reliable and valid background information and using databases for research seemed to be very challenging for many of the students. They discovered thatthe kind of information which is needed in academic research cannot be retrieved quickly by a Google search or from Wikipedia. Moreover, some students were not pleased that entering one's research question into Google did not produce immediately useable results, as the interview results revealed.

In this age of cut-and-paste, it was also hard for some of the students to understand why one needed to rewrite or paraphrase the information once it had been retrieved from a journal article or a website. Issues of copyright and plagiarism did not seem to be very relevant.This could be because students use the internet to retrieve short pieces of information, so reporting it onwards, typically orally, is not an issue.

\section{Conclusions and recommendations}

All in all it was evident that the engineering students in the case study struggled in developing their academic literacy skills. It could be argued that some of the students were not really interested in studying engineering and were therefore not engaged in learning or willing to commit any extra time to their studies. However, the most likely reason is that the students had opted for a degree in engineering and came to the HEI of their choice with good skills in physics and mathematics and with a mindset prepared to take on the challenges of learning about engineering from their engineering instructors. This is why an academic literacy skills course taught by English teachers at the beginning of the first year in an engineering HEI seems perhaps somewhat out of place to the students.

The indicators that students had problems with, which arose from study [20], revealed that academic literacy skills are an umbrella for a multitude of smaller skill sets, such as digital literacy skills, research skills, academic writing skills, document formatting, etc. These skills are all necessary tools for survival in higher education and students have to acquire them. To date there have been a variety of approaches to providing students with such skills, as mentioned earlier in the context of WAC, WID, study skills and courses on English or writing for academic 
purposes. However, students still struggle to acquire these skills, especially in engineering colleges [2].

\subsection{Recommendations}

The recommendation of the current study is to align the teaching of these skills with the six engineering habits of mind discussed above [7] to make it easier for mathematically minded engineering students to comprehend them. Each engineering habit of mind could be related to academic literacy skills, for instance, as follows;

Since systems thinking deals with whole systems and parts and how they connect [7], all the subskill sets related to academic literacy skills could be taught in these terms to engineering students.

Problem-finding is about clarifying needs, checking existing solutions and investigating contexts [7], and these aspects could be provided to serve as guidelines for focusing on issues to be researched and for finding appropriate sources for one's research. Students could be aided in this by training them to research relevant information by starting with simple sources such as images and diagrams before moving on to complex explanations in writing be it from professional reports or scholarly journal articles.

To be able to visualize means to be able to move from abstract ideas to concrete ones [7]. This is already a demanding feat for students, but in the context of academic literacy skills, it could be related to explaining results which have been displayed in charts and graphs, for example.

Improving, in the context of engineering habits of mind, means restlessly trying to make things better by experimenting [7], among other things, and this could be related to solid discussions and even to proofreading.

Creative problem-solving is one of the most demanding parts of the framework. It is related to applying techniques from different traditions and generating ideas and solutions with others [7]. It is a skill that can be developed over timeas students' disciplinary knowledge increases. Practicing teamwork would also be useful in this context, as most engineers in the workplace do.

Another big challenge for students is the final habit of mind, namely adaptability, which requires students to comprehend the kinds of possibilities brought about by change both physically and mentally [7]. Especially for students such as the ones in the current case study, who have a rote-learning background from school, this kind of thinking requires a lot of unlearning and relearning.

An additional recommendation could be for academic literacy skills to be taught by engineering instructors either on a special course or as curriculum-infusedmatters, for example when dealing with a laboratory report. Unfortunately, as studies $[2,3]$ show, engineering instructors understand that the kind of work involved in acquiring academic literacy skills, especially writing, is not popular among engineering students. Moreover,helping students acquire these skills is not the subject matter they have specialized in, so they prefer not to focus on it. As a result, such skills are usually taught by writing specialists or English language instructors, both with a humanities background. For many of these instructors engineering subject matters may be as foreign as academic literacy skills are to engineering instructors.

The conundrum is that the variety of skills that students need to become competent in academic literacy skills does not pertain to any particular academic field. Ideally cooperation from both types of instructors would provide the students with the best possible knowledge on academic literacy skills, but this could be problematic due to epistemological differences and lack of knowledge regarding both types of instructors. The level of cooperation required would also demand a lot of time, which is not always readily available for instructors in $\mathrm{HE}$ who are often obliged to do research and administrative work in addition to teaching students.

The point is that it could be argued that the problems that engineering students face regarding the development of their academic literacy skills are due to a mismatch in the approaches of academic literacy skills instructors and the mindset of the students. Engineers methodologically follow systems or processes to arrive at a useful, functional end. They need to understand systems and substructures, and to work their way through processes to arrive at feasible solutions. However, despite the variety of matters covered within the domain of academic literacy skills, they are rarely broken down into small enough entities for students to easily understand. This is difficult also because most of the matters relate to one another and cannot therefore be discussed separately. On the other hand, relating matters to each other is the lifeblood of systems thinking, an important engineering habit of mind [7], as areproblem finding, problem solving and visualization. It is therefore the recommendation of this study to present academic literacy skills in future to engineering students by using the framework of engineering habits of mind, thus enhancing the students' ability to develop both their academic literacy skills and engineering thinking habits. A model of such a framework is currently being developed by the researcher of the current study.

Researching the possibility of a similar, equivalent framework for teaching academic literacy 
skills within disciplines with strong professional epistemologies such as business, law and medicine could prove to be equally useful for students, subject matter instructors and academic literacy skills instructors.

The current study had some shortcomings. More interviews with both students and faculty could have produced an even more thorough view of the students' academic literacy skills development. Furthermore, an analysis of students' emerging thought patterns within their written work could have assisted the researcher in understanding the students' current thought patterns better and how they relate more clearly to the engineering habits of mind. In addition,the current study of integrating academic literacy skills could have included interviews with alumni and other working engineers in order to gain a deeper insight into engineering habits of mind and to add to the field of knowledge of the epistemology of engineering. These were not done due to time constraints, but they hopefully provide scope for further studies.

\section{References}

[1] S. Bury, R. Sheese and S. Katz.” Literacies Information and beyond: The Learning Commons and the embedding of academic literacy instruction in disciplinary courses." Paper presented at WILU Conference, May 8-10 2013. University of New Brunswick, Fredericton, NB. Retrieved November 15, 2013, http://yorkspace.library. yorku.ca/xmlui/handle/10315/26588?show=full.

[2] C. B. Cilliers. "Student perception of academic writing skills activities in a traditional programming course."Computers \& Education, 58(4), 2012, pp. 10281041.

[3] U. Wingate, N. Andon and A. Cogo. "Embedding academic writing instruction into subject teaching: A case study."Active Learning in Higher Education, 12(1), 2011, pp. $69-81$.

[4] K. Chanock, C. Horton, M. Reedman, \& B. Stephenson. "Collaborating to embed academic literacies and personal support in first year discipline subjects."Journal of University Teaching \& Learning Practice, 9(3), 2012, p. 3.

[5] B. Palmer and R. M. Marra. "College student epistemological perspectives across knowledge domains: A proposed grounded theory.'Higher Education, 47, 2004, pp. 311-335.

[6] D. R. Russell, M. Lea, J. Parker, B. Street and T. Donahue. "Exploring notions of genre in 'academic literacies' and 'writing across the curriculum': Approaches across countries and contexts." In: C. Bazerman, A.Bonini, \& D. Figueiredo. (Eds.). 2009. Genre in a changing world.
Perspectives on writing. Fort Collins, Colorado: The WAC Clearinghouse and Parlor Press. Available at http://wac.colostate.edu/books/genre/

[7] Royal Academy of Engineering. "Thinking like an engineer: implications for the education system." Royal Academy of Engineering.Full Report. May 2014.

[8] C. Thaiss, and T. Porter. "The state of WAC/WID in 2010: Methods and results of the US survey of the international WAC/WID mapping project."College Composition and Communication, 61(3), 2010, 534-570.

[9] D. R. Russell. "Contradictions regarding teaching and writing (or writing to learn) in the disciplines. What we have learned in the USA."REDU Revista di Docencia Universitaria, 11(1), 2013, pp. 161-181.

[10] M. Lea and B. Street. "The "academic literacies" model: Theory and applications."Theory into Practice, 45(4), 2006, pp. 368-377.

[11] B. Street. "Academic literacies approaches to genre?" Studies (V SIGET), 2009, pp. 347-361.

[12] D. Grasso and M. B. Burkins."Beyond technology: The holistic advantage.'In Holistic Engineering Education (pp. 1-10).Springer.New York, 2010.

[13] D. Martinez, C. Wells, C. Hannigan, T. Peterson and C. Stevenson. Technical Writing. Kaplan Publishing, New York, 2011.

[14] W. Archer and J. Davison.Graduate employability. The Council for Industry and Higher Education, 2008.

[15] M. Morgan and P. O'Gorman."Enhancing the employability skills of undergraduate engineering students.”W. Aung, 152, 2011, pp. 239-246.

[16] C. Montgomery. "A decade of internationalization. Has it influenced students' views of cross-cultural group work at university?" Journal of Studies in International Education, 13(2), 2009, pp. 256-270.

[17] J. A. Jenkins, M. Cogo and M. Dewey. "Review of developments in research into English as a lingua franca.'Language Teaching 44/3, 2011, pp. 281-315.

[18] M. J. Riemer. "Communication skills for the 21st century engineer." Global Journal of Engineering Education, 11(1), 2007.

[19] H. Idrus, R. Salleh and M. R. T. L. Abdullah, (2011). "Oral communication ability in English: An essential skill for engineering graduates."Asia Pacific Journal of Educators and Education, 26(1), 2011, pp. 107-123.

[20] M. Hatakka."Indicators affecting the development of first year students' academic literacy skills in an Englishmedium higher education institute in the Arabian Gulf region." Doctoral thesis, University of Exeter, UK. 2014. 